\title{
Article \\ Wettability and Water Uptake Improvement in Plasma-Treated Alfalfa Seeds
}

\author{
Matej Holc ${ }^{1, *}$, Peter Gselman ${ }^{2}$, Gregor Primc ${ }^{1} \mathbb{D}$, Alenka Vesel ${ }^{1} \mathbb{D}$, Miran Mozetič ${ }^{1}$ and Nina Recek ${ }^{1}$ (D) \\ 1 Jožef Stefan Institute, Jamova Cesta 39, 1000 Ljubljana, Slovenia; gregor.primc@ijs.si (G.P.); \\ alenka.vesel@ijs.si (A.V.); miran.mozetic@ijs.si (M.M.); nina.recek@ijs.si (N.R.) \\ 2 Interkorn Ltd., Gančani 94, 9231 Beltinci, Slovenia; peter.gselman@interkorn.si \\ * Correspondence: matej.holc@ijs.si
}

check for updates

Citation: Holc, M.; Gselman, P.; Primc, G.; Vesel, A.; Mozetič, M.; Recek, N. Wettability and Water Uptake Improvement in Plasma-Treated Alfalfa Seeds. Agriculture 2022, 12, 96. https:// doi.org/10.3390/agriculture12010096

Academic Editor: Joshua D. Klein

Received: 9 December 2021

Accepted: 6 January 2022

Published: 11 January 2022

Publisher's Note: MDPI stays neutral with regard to jurisdictional claims in published maps and institutional affiliations.

Copyright: (C) 2022 by the authors. Licensee MDPI, Basel, Switzerland. This article is an open access article distributed under the terms and conditions of the Creative Commons Attribution (CC BY) license (https:// creativecommons.org/licenses/by/ $4.0 /)$.

\begin{abstract}
The cultivation of alfalfa (Medicago sativa L.), a forage crop grown worldwide, is negatively affected by hard seed presence. We show that treatment of alfalfa seeds with an inductively coupled radio frequency oxygen plasma improves their surface hydrophilicity, as determined by water contact angle (WCA) measurements and water uptake. Furthermore, we see that these effects are mediated by functionalization and etching of the alfalfa seed surface. Surface chemistry is analyzed by X-ray photoelectron spectroscopy (XPS), while morphology is viewed using scanning electron microscopy (SEM). Plasma produces effective alfalfa seed hydrophilization with a variety of treatment parameters. With its potential for fine-tuning, plasma modification of seed wettability shows promise for introduction into agricultural practice.
\end{abstract}

Keywords: alfalfa; seed; wettability; water uptake; surface modification

\section{Introduction}

Alfalfa (Medicago sativa L.), also known as lucerne, is a forage crop grown around the world and is commonly considered the most important forage legume due to its high yield and quality. It is used for the production of hay and silage and is grown on pastures [1]. The plant is related to clovers, i.e., plants of the genus Trifolium, which it also visually resembles. Both genera are part of the vicioid subclade of the legume family Fabaceae [2]. Advantages of crop legumes, as opposed to grasses, are their high protein content, due to the ability of biological $\mathrm{N}_{2}$ fixation, and their better palatability [1].

Cultivation of alfalfa is to this day negatively affected by the significant proportion of hard seeds among seeds batches [3]. The term "hard seeds" refers to seeds in which the seed coat is impermeable to water. This acts as a form of exogenous dormancy, wherein hard seeds fail to germinate due to lack of water availability, which, in the wild, preserves the viability of such seeds over a longer time range [4]. Depending on the cultivar, the proportion of hard seeds in alfalfa may be high. If this percentage is sufficiently high, such a batch of seeds may be unsuitable for commercial use [3]. E.g., in Slovenia, the legally required minimal germination percentage (GP) for alfalfa is $80 \%$, while the highest allowed hard seed percentage is $40 \%$ [5]. Storage of seeds at room temperature does not necessarily reduce hard seed content, even over the period of several years; meanwhile, during storage at low temperature, the hard seed content does not decrease reliably $[3,6]$. As a way to circumvent this natural seed property for agricultural purposes, seed coat permeability should be increased. This is typically achieved through scarification of the alfalfa seed coat, which allows for improvement of seed water uptake [7]. Scarification methods range from mechanical, which inflicts minor damage to the seed coat, to freeze-thawing and brief hightemperature treatments. However, due to their nature, such methods can also negatively affect seed lots [3]. One example is seed injury as a result of freeze-thaw scarification, which may not manifest during initial testing [8]. Mechanically manipulated seeds are also 
more susceptible to bacterial or fungal infection [9]. Furthermore, the quality of scarified seed typically deteriorates with storage [6].

An alternative way to modify seed surface properties is the use of low-temperature plasma systems. Typically, plasma treatment of seeds will increase surface hydrophilicity, which in turn enables increased water uptake into the seed $[10,11]$. Plasma discharges in oxygen-containing gases are known to introduce oxygen-containing functional groups to surfaces of materials, including agricultural seeds. In addition, plasma treatment may etch the seed surface or result in physical cracks $[12,13]$. We have recently reviewed the relation between wettability increase and germination improvement in seeds as a result of plasma treatment and found a positive correlation between the change in the water contact angle (WCA) and the GP, despite scattered results [14]. Plasma treatments at moderate conditions and exposure times are unlikely to negatively affect seed lots, as temperatures remain moderate [15], and reactive plasma species typically only affect the outer few nanometers of the seed surface. In addition, vacuum ultraviolet (VUV) radiation may affect deeper structures, typically in the range of a few $10 \mathrm{~nm}$ [16].

Interestingly, plasma treatment of alfalfa seeds began as early as the 1960s, when Nelson et al. used a low-pressure glow plasma system to reduce seed hardness and positively affect germination, publishing their results in 1983 [6]. At suitable levels of exposure, they increased the percentage of normal seedlings and decreased the hard seed percentage. Even in seeds stored for as long as 19 years, where the hard seed percentage decreased naturally, treated seed lots have still shown better results than untreated control seeds. However, in those experiments, separate radio frequency (RF) electric field and infrared treatments were about as effective as the plasma treatment in achieving such results [6].

Following a gap of several decades, interest in plasma treatment of alfalfa seeds began to arise again with the emergence of plasma agriculture. An array of papers published since 2016 concern the treatment of alfalfa seeds with a variety of plasma systems. All such papers, along with the 1983 publication, are summarized in Table 1.

Table 1. Overview of currently available research concerning the treatment of alfalfa seeds with gaseous plasma.

\begin{tabular}{|c|c|c|c|c|c|c|}
\hline Author & Year & Plasma & Gas & Pressure & $\begin{array}{l}\text { Treatment } \\
\text { Time [s] }\end{array}$ & Effect \\
\hline Nelson [6] & 1983 & glow & air & low & / & $\begin{array}{c}\uparrow \text { germination; } \downarrow \text { hard seed \%; } \\
\text { long-lasting effects }\end{array}$ \\
\hline Butscher [17] & 2016 & pulsed DBD & $\mathrm{Ar}$ & atm & $120-900$ & $\begin{array}{l}\text { decontamination; } \uparrow \text { germination under } \\
\text { mild conditions }\end{array}$ \\
\hline Tang [18] & 2016 & glow & $\mathrm{Ne}$ & low & 20 & $\uparrow$ germination; $\uparrow$ vigor \\
\hline Feng [19] & 2018 & CC RF & air $/ \mathrm{He}$ & low & 15 & $\begin{array}{c}\uparrow \text { germination; } \uparrow \text { vigor; under simulated } \\
\text { drought stress }\end{array}$ \\
\hline Luan [20] & 2020 & corona & air & atm & / & $\begin{array}{c}\downarrow \text { WCA, } \uparrow \text { water uptake, changes to } \\
\text { surface chemistry (FTIR)/morphology } \\
\text { (SEM) }\end{array}$ \\
\hline $\begin{array}{l}\text { Machado- } \\
\text { Moreira } \\
\text { [21] }\end{array}$ & 2021 & $\operatorname{arc}$ & air & atm & 600 & $\begin{array}{l}\text { PAW: decontamination; unaffected } \\
\text { germination and growth }\end{array}$ \\
\hline
\end{tabular}

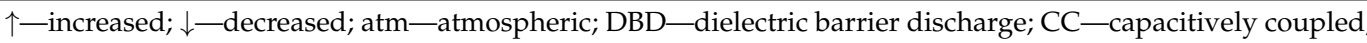
$\mathrm{RF}$-radiofrequency; WCA—water contact angle; FTIR—Fourier transform infrared spectroscopy; SEM-scanning electron microscopy; PAW-plasma-activated water.

Given the importance of seed hardness to alfalfa cultivation [3], it is surprising that only one of the recent publications addresses the wettability of the seed surface. In the paper by Luan et al., the authors treated alfalfa seeds using an alternating current (AC) corona discharge in ambient air and found that the resulting changes to seed coat chemistry and morphology resulted in changes to the seed hydrophilicity and water uptake [20]. 
Of the remaining papers, two have mainly considered the effects of plasma treatment directly on alfalfa seed germination. Tang et al. [18] have treated alfalfa seeds with a glow discharge at low pressure, using neon as the process gas. They found that the treatment at suitable conditions stimulated germination rate and germination vigor. Feng et al. [19] germinated seeds under simulated drought stress and found that treatment of seeds with a low-pressure, capacitively coupled (CC) RF plasma using air/helium improved an array of germination and seedling growth parameters, including germination rate, seedling height, and root length. The remaining two papers mainly considered plasma decontamination of alfalfa seeds; one used a pulsed dielectric barrier discharge (DBD) in argon to decrease $E$. coli presence on the seed surface [17], while the other soaked the seeds in plasma-activated water (PAW) to disinfect the seed of various pathogens [21]. The DBD treatment also improved the germination probability at mild treatment conditions but negatively affected it if the treatment time, pulse frequency, or voltage were increased [17]. PAW treatment, in turn, increased sprout length, but the effect on the growth rate was not statistically significant [21].

To understand the observed effects of plasma on the surface chemistry and morphology, as well as their relation to alfalfa seed wettability and water uptake (WU) improvement, we have approached the plasma treatment of alfalfa seeds systematically. We used a lowpressure, inductively coupled (IC) RF plasma in both the E-mode and the H-mode to treat the seeds. At lower generator powers of the RF generator, the discharge in the IC plasma is characterized by low electron density, relatively high electron temperature, and low light emission. Such a discharge is called an E-mode discharge, which is considered to have a negligible induced electric field in the coil compared with the voltage drop between the coil and the reactor wall. By increasing the generator power, a certain critical value is reached when the plasma luminosity and density of electrons increase, while electron temperatures slightly decrease. This is the $\mathrm{H}$-mode discharge, where the induced azimuthal electric field predominates over the axial one [22].

We used oxygen as the process gas to hydrophilize the seed surface. Furthermore, we used the same array of treatment parameters for the seeds to be used in all analyses in order to compare the treatment effects directly. To the best of our knowledge, this is the first paper using X-Ray photoelectron spectroscopy (XPS) to analyze alfalfa seed surface chemistry after plasma treatment of seeds.

\section{Materials and Methods}

\subsection{Seed Material}

Seeds of alfalfa (Medicago sativa L.) were obtained from Interkorn Ltd. (Gančani, Slovenia). Visually healthy and undamaged seeds were selected for use in the experiments. Before the experiments, seeds were kept in a dry atmosphere at room temperature.

\subsection{Plasma Reactor}

For the treatment of seeds, we employed an in-house, pilot-scale plasma system which operates in the pressure range between 1 and $100 \mathrm{~Pa}$. Plasma was inductively coupled with an RF generator via a coil and a matching network optimized for the IC plasma in the H-mode. The reactor in which seed samples were treated was a glass tube $800 \mathrm{~mm}$ in length and $36 \mathrm{~mm}$ inner diameter. The reactor was continuously pumped using a twostage oil rotary vacuum pump that had a nominal pumping speed of $80 \mathrm{~m}^{3} / \mathrm{h}$. At the same end as the pump, a simple air inlet valve was placed for venting the whole vacuum system. Commercially available oxygen of $99.99 \%$ purity was introduced at the opposite end of the tube by a flow controller AERA FC7700 (Advanced Energy, Fort Collins, CO, USA), calibrated for argon at $20^{\circ} \mathrm{C}$. A Baratron absolute pressure gauge (MKS Instruments, Andover, MA, USA) was used to monitor the pressure inside the reactor. A 6-turn watercooled copper coil with a length of $70 \mathrm{~mm}$ was wrapped around the tube, and a Cesar 1310 RF power generator (Advanced Energy, Fort Collins, CO, USA), operating at $13.56 \mathrm{MHz}$, was coupled to the coil via a matching network. The experiments were performed at a fixed 
output power of 50 or $300 \mathrm{~W}$ to achieve E- or H-mode plasma, respectively. A schematic representation of the system is seen in Figure 1.

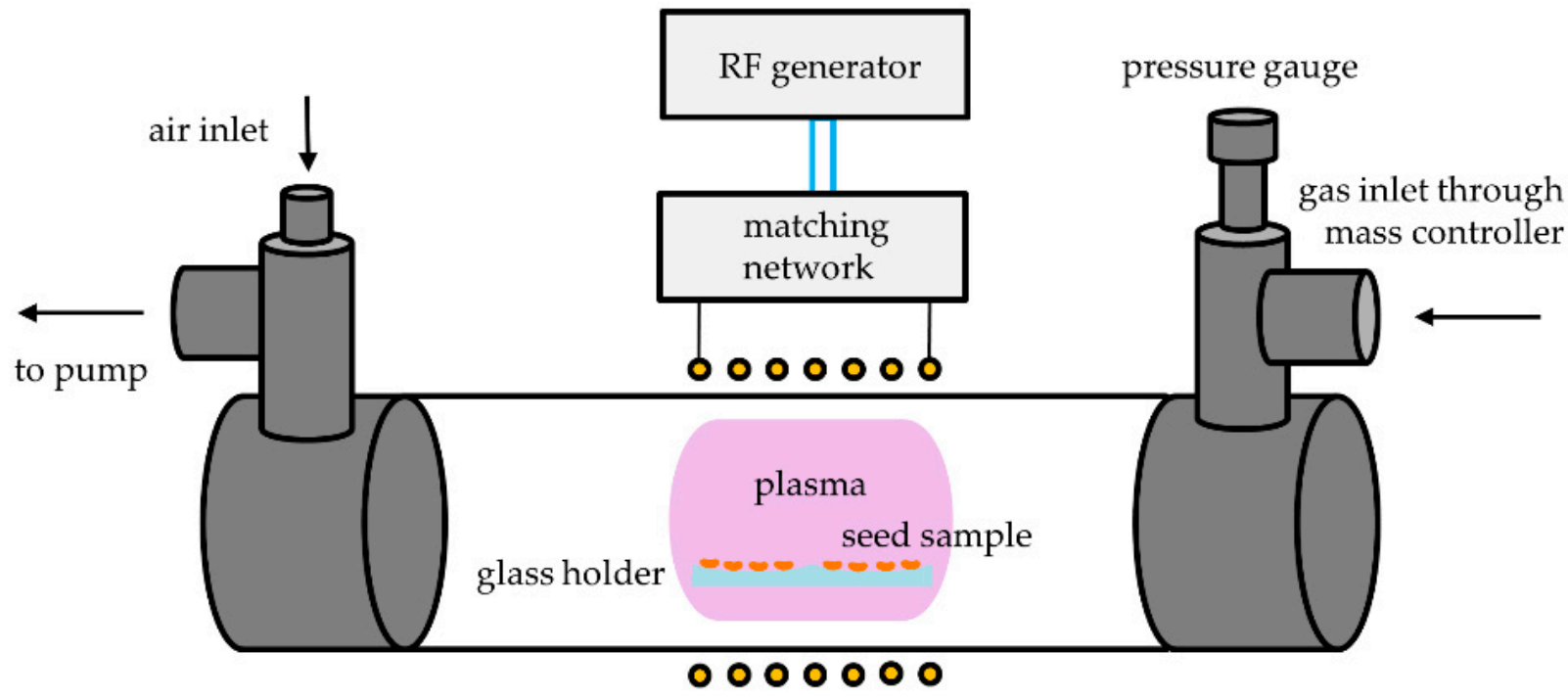

copper coil

Figure 1. Schematic representation of the plasma system used for the treatment of bean seeds. Adapted from Recek et al. [23].

\subsection{Plasma Treatment}

During each treatment, 100 alfalfa seeds were treated simultaneously. The seeds were placed into a concave recess of a glass holder and positioned in the middle of the copper coil, as shown in Figure 1. The E-mode plasma is fairly uniformly distributed along the discharge tube, while the H-mode plasma is mostly spatially enclosed within the coil. In both cases, the seeds were directly exposed to the glowing plasma. The discharges were ignited at a pressure of $25 \mathrm{~Pa}$. The output power $\left(\mathrm{P}_{\mathrm{O}}\right)$ at the generator was $50 \mathrm{~W}$ for the E-mode and $300 \mathrm{~W}$ for the H-mode. Treatment times were $0,10,30,60,90$, and $120 \mathrm{~s}$ for the E-mode and $0,0.3,1,3$, and $5 \mathrm{~s}$ for the H-mode. The times of $120 \mathrm{~s}$ and $5 \mathrm{~s}$ were the longest suitable treatment times for the $\mathrm{E}$ - and $\mathrm{H}$-mode, respectively. Longer treatment times caused visible damage to the seeds during preliminary experiments and were thus not considered for inclusion.

\subsection{Water Contact Angle}

To determine the surface wettability, WCA was measured on untreated and plasmatreated alfalfa seeds. Static WCA by the sessile drop method for picoliter droplets was evaluated using the Drop Shape Analyzer DSA 100 (Krüss GmbH, Hamburg, Germany). A droplet of deionized (DI) water with a volume of approximately $\mathrm{V}=0.002 \mu \mathrm{L}$ was placed onto the alfalfa seed surface. The measurements were performed at ambient conditions, immediately after plasma treatment. The measurement on each sample was performed 1-4 times, while the sample at each treatment condition was prepared in triplicate. A mean value and standard error were calculated.

\subsection{Water Uptake}

We determined WU by the seeds as follows. Immediately after plasma treatment, each sample of 100 seeds was placed in a microcentrifuge tube and water was added on top of the seeds. To prevent seeds from floating on the surface, the microcentrifuge tubes were shaken by hand and then left steady for seeds to soak. Soaking times were as follows: 30, 90,150 , and $300 \mathrm{~min}$. Before weighing the seeds, the water was removed, and the seeds were placed on a paper towel to remove excess water. We calculated the absolute WU by 
subtracting the dry seed mass after plasma treatment from the seed mass after soaking, and then determined the relative WU. The measurements were performed in duplicate, and a mean value and standard error were calculated.

\subsection{Scanning Electron Microscopy}

We used an environmental SEM to obtain images of the alfalfa seed surface at high magnification (up to 10,000×). Environmental SEM enables scanning without the additional coating of the sample surface, even at high magnifications. The seeds were attached to an aluminum holder using conductive carbon tape. The SEM images were obtained using a Quanta 650 ESEM (Thermo Fisher, Waltham, MA, USA).

\subsection{X-ray Photoelectron Spectroscopy}

The elemental composition of the seed surface, expressed in atomic percent (at.\%), was determined by XPS (Physical Electronics, Ismaning, Germany). After the seeds were fixed and placed on the sample holder, they were left inside the XPS chamber to dry for an hour before the analysis. The analyzed area of the sample was $400 \mu \mathrm{m}^{2}$, excited by X-ray radiation from a monochromatic $\mathrm{Al}$ source at a photon energy of $1486.6 \mathrm{eV}$ and a take-off angle of $45^{\circ}$. XPS survey scan spectra were acquired at a pass energy of $187 \mathrm{eV}$ using an energy step of $0.4 \mathrm{eV}$. Spectra were analyzed using the MultiPak V8.0 software (Ulvac-phi, Inc., Chigasaki, Japan). All measurements were performed in duplicate, and a mean value and standard error were calculated.

\subsection{Statistical Analysis}

JASP 0.9.2. open-source software (University of Amsterdam, Amsterdam, The Netherlands) was used for statistical analysis of data from WCA, WU, and XPS. ANOVA and the post hoc Tukey's range test were used to calculate and compare group means. Differences in the means were considered statistically significant at $(p<0.05)$. Where error bars are shown in charts, they represent standard error.

\section{Results and Discussion}

\subsection{Water Contact Angle}

WCA measurements are shown in Figure 2. For both the E-mode and the H-mode treatment, the WCA drops substantially after the shortest treatment time, after which the WCA decreases more gradually. The difference is statistically significant in all instances except between treatments of 30 and $60 \mathrm{~s}$ in the E-mode and between treatments of 3 and 5 $\mathrm{s}$ in the H-mode.

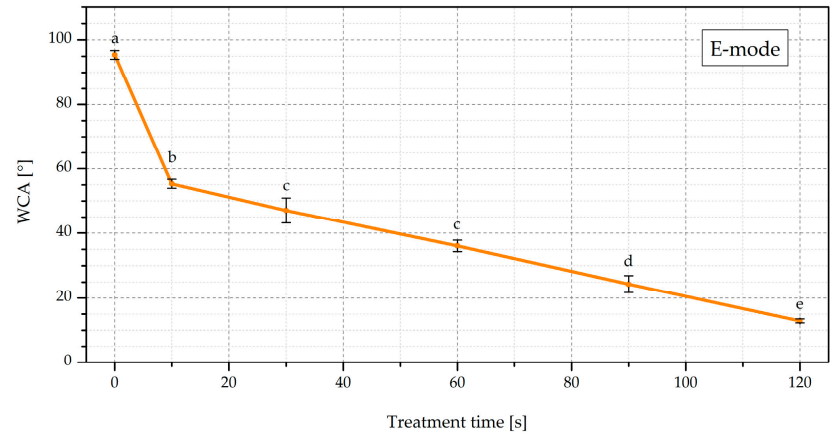

(a)

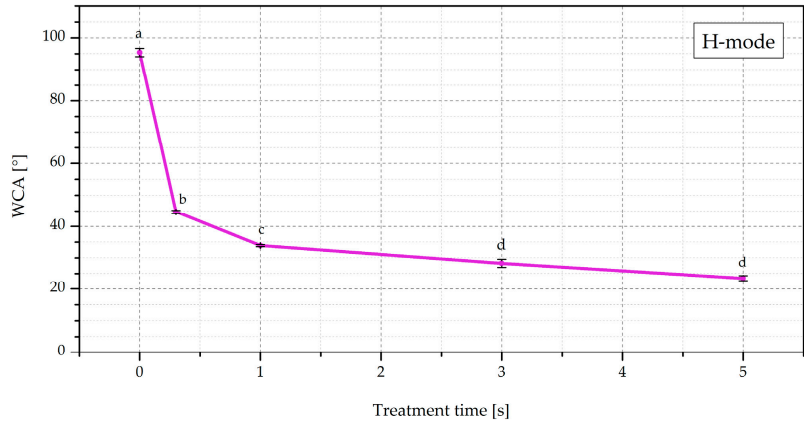

(b)

Figure 2. Water contact angle (WCA) on the alfalfa seed surface after treatment with an (a) E mode or (b) H-mode plasma at various treatment times. The error bars represent standard error. Different lowercase letters above data points represent statistically significant differences $(p<0.05$; post hoc Tukey's range test) between treatments. 
We see from Figure 2 that, after the longest feasible treatment times, the E-mode treatment results in a WCA around $13^{\circ}$, while the $\mathrm{H}$-mode achieves a WCA of about $25^{\circ}$. While the E-mode reaches a comparable result at a treatment time of $90 \mathrm{~s}$, the H-mode plasma is able to achieve this in a substantially shorter time due to a higher density of reactive plasma species [22]. Treatment with plasma, especially when using an oxygenor nitrogen-containing gas, is known to increase seed surface wettability [14]. This is achieved through mechanisms of functionalization and etching, as will be seen in the results of the XPS and SEM analyses. While some treatments are able to reduce WCA on seeds to immeasurably low values [23-27], thereby achieving effectively complete wetting of the seed surface, the end result depends on the seed properties and selected process parameters. Often, notable WCA decreases were achieved particularly through the use of IC RF plasmas [23-25].

When Luan et al. treated alfalfa seeds with a corona discharge at atmospheric pressure, they reduced the WCA of the seeds from about $130^{\circ}$ to about $75^{\circ}$ [20]. The significantly higher initial WCA may relate to a difference in the cultivar, seed storage, or other similar reason. The less prominent WCA reduction might be due to the use of a corona discharge, which is inhomogeneous in nature [28]. Consequently, surface modification and the resulting wettability changes may be less extensive. To the best of our knowledge, this is the only available study measuring alfalfa seed surface wettability. There are also no further publications concerning the WCA after plasma treatment for seeds of other related legume species from the genera Medicago, Trifolium, or Melilotus.

\subsection{Water Uptake}

Along with wettability, we investigated whether the plasma treatment increases the WU of alfalfa seeds. From Figure 3, it is evident that the WU does indeed increase, and that increasing the treatment time also results in a larger WU improvement. As with the WCA, the result after the longest feasible treatment time is comparable for the E-mode and H-mode treatments, namely a relative WU improvement of about $140 \%$, which is about a $20 \%$ increase compared with the untreated control. For the E-mode treatment, the increase is statistically significant for all treatment times at $30 \mathrm{~min}$ of soaking, but not at longer soaking times, except for the $120 \mathrm{~s}$ treatment at $150 \mathrm{~min}$ of soaking. For the H-mode treatment, the WU of treated seeds is significantly larger than the WU of control seeds for the $5 \mathrm{~s}$ treatment at 90 and $300 \mathrm{~min}$ of soaking.

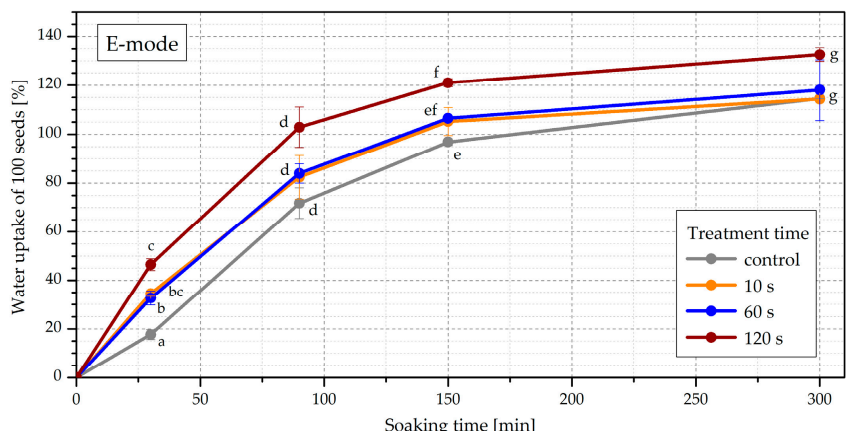

(a)

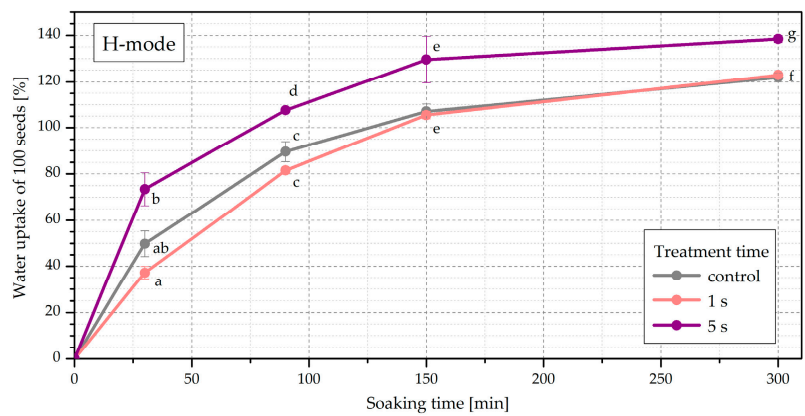

(b)

Figure 3. Water uptake of 100 alfalfa seeds after treatment with (a) an E-mode plasma or (b) an $\mathrm{H}$-mode plasma at selected treatment times and soaked in water. The error bars represent standard error. Different lowercase letters next to data points represent statistically significant differences $(p<0.05$; post hoc Tukey's range tests) between treatments at each individual soaking time.

Again, only Luan et al. have so far measured WU of alfalfa seeds after plasma exposure. They soaked a set amount of seeds in water for $20 \mathrm{~h}$ and found that treatment at all selected conditions improved the water uptake, whereby the improvement seemed independent of 
the applied voltage [20]. A recent review points out several instances where the imbibition was increased after plasma treatment of legume seeds [29]. This includes treatment of Mimosa caesalpiniafolia [11] and pea seeds [12] with air DBD plasmas, as well as treatment of soybean with an air DBD plasma utilizing $\mathrm{O}_{2}$ or $\mathrm{N}_{2}$ as a carrier gas [30]. In our own research, the treatment of bean seeds with the same plasma system, as used in this work, also improved the WU of the sample [23].

The suggested mechanism of improved imbibition after plasma treatment of seeds is increased availability of water at the seed surface due to functionalization, as well as modification of the protective surface layers of the seed [11,26]. Several authors have postulated a direct correlation between WCA and WU of plasma-treated seeds, including those researching legumes such as beans [31] and Mimosa caesalpiniafolia [11]. Furthermore, one recent publication has resolved the water path in plasma-treated seeds of another Fabaceae species, namely Leucaena leucocephala. It found that plasma, by hydrophilizing the surface of the seed coat, managed to increase water absorption into the seeds, overcoming the resistance barriers to water penetration [9].

\subsection{Scanning Electron Microscopy}

SEM images of the alfalfa seed surface are collected in Figure 4. The untreated alfalfa seed surface has a regular pattern of bumpy protrusions throughout. After short treatment times (E-mode, $30 \mathrm{~s} ; \mathrm{H}$-mode, $1 \mathrm{~s}$ ), no changes to the surface morphology were detected. After treatments with the longest feasible treatment times of either E-mode or H-mode plasma, etching of the surface is apparent, as the bumps become eroded, and the entirety of the surface is thereby notably rougher. In Figure $4 c, d$, we see that after E-mode treatment for $120 \mathrm{~s}$, the etching is sufficient that cracks appear at the seed surface.

The native seed surface we see under SEM is consistent with the observations of other authors, either those researching the topography of alfalfa seeds [32] or treating them with plasma $[17,20]$. Only Luan et al. have examined the alfalfa seed surface after plasma treatment. Similar to our observations, their micrographs showed etching of the surface protrusions and the appearance of fine grooves. Furthermore, the authors also found an increase in the frequency and area of surface cracks, particularly in the seeds directly exposed to plasma, as opposed to covered with a Petri dish during treatment [20]. Conversely, Butscher et al. have taken SEM images of the alfalfa seeds before, but not after, exposure to plasma [17].

Plasma etching of seed surfaces was previously demonstrated in several species of the genus Fabaceae. The surface of the pea seed had similarly elaborate protruding structures, which became increasingly etched and exposed with plasma treatment [33,34]. Specifically, protrusions were etched more intensely than depressions of the surface [12]. In seeds of common bean, a short, powerful IC RF oxygen plasma etched and eroded the otherwise reasonably smooth surface [23], and the irregular surface of mung bean seeds was similarly eroded by an atmospheric pressure microplasma array [35].

When plant seeds are exposed to plasma, etching occurs at their very outer surface, which is a hydrophobic waxy layer called the cuticle [36]. Cuticular waxes are commonly made up primarily of long-chain, saturated hydrocarbons with additional oxygen-containing functional groups. Etching is achieved by the gradual degradation and erosion of these waxy materials [37]. In seeds of black gram, for example, a rough waxy surface was notably eroded by the use of an air DBD plasma [38]. Indeed, in several legume species, the hardness of the seeds appears to be related to the thickness of the seed coat and of the cuticle itself [39], while loss of cuticular lipids has been associated with seed softening [40]. Furthermore, the physical dormancy of pea seeds was found related to the impermeability of the interface between the waxy cuticle and the cell wall of the underlying macrosclereid cells, called the "light line" [41]. The permeability level of the alfalfa seed coat was also found related to its thickness, and the variation in macrosclereid cell length was determined to be one of the influencing factors [42]. In Leucaena leucocephala seeds, this resistance barrier to water penetration was similarly identified as the surface of the 
seed coat along with the light line and was possible to overcome by plasma treatment [9]. Research on fenugreek seeds has additionally found that exposure to an atmospheric pressure plasma jet has progressively peeled off macrosclereid cells from the surface of the seeds $[43,44]$.

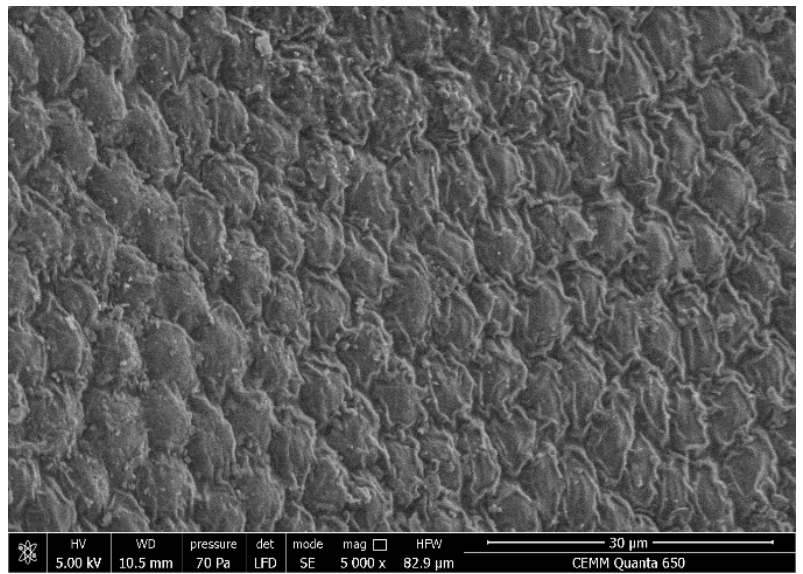

(a)

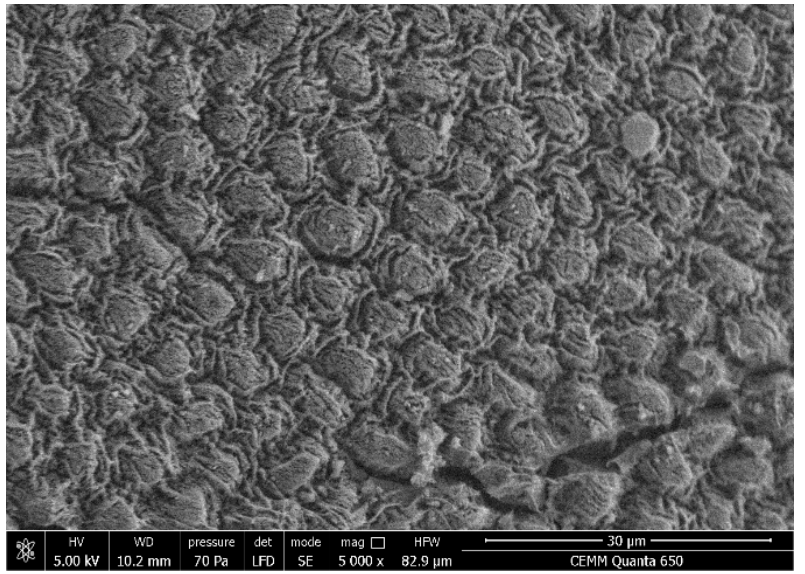

(c)

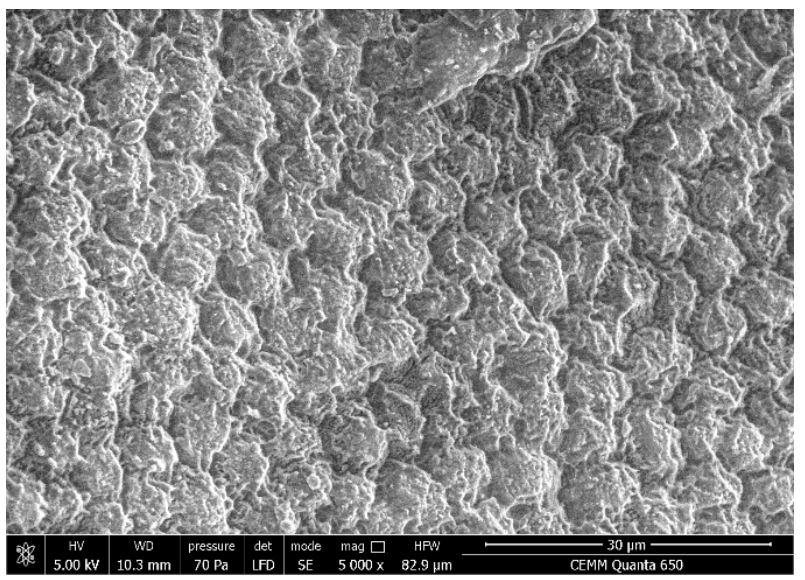

(e)

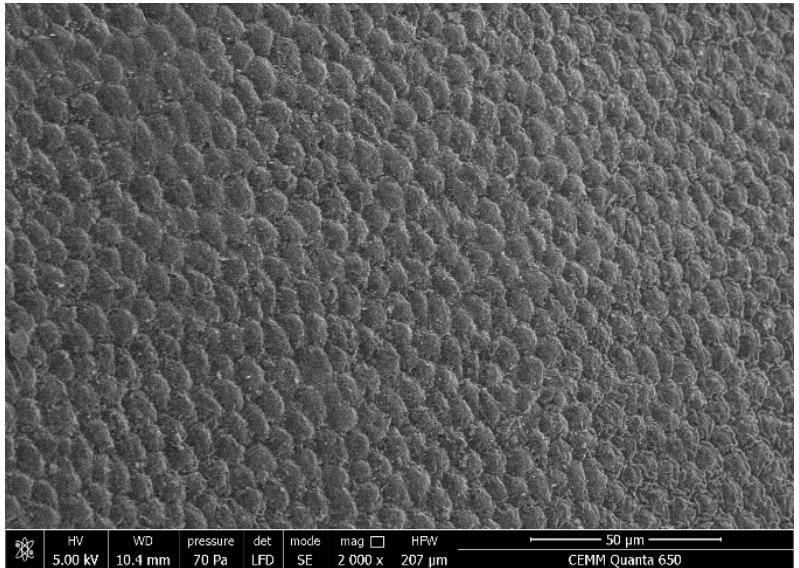

(b)

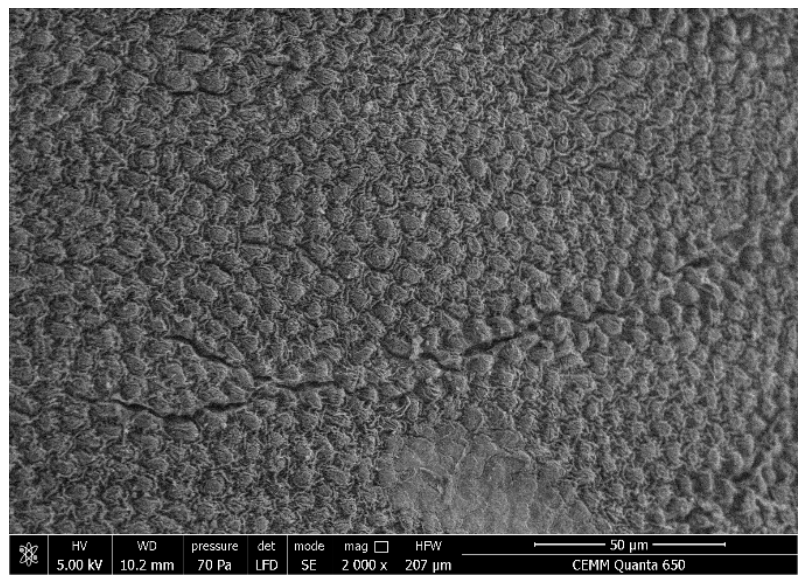

(d)

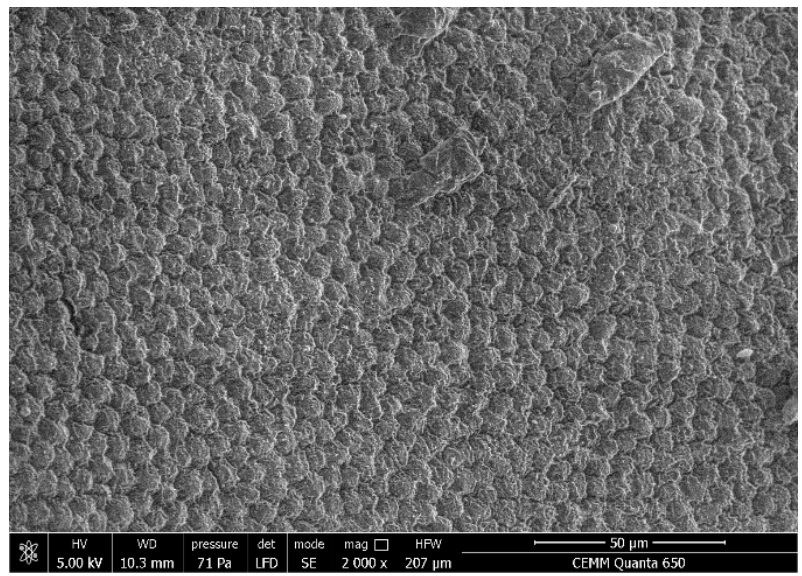

(f)

Figure 4. Alfalfa seed surface as seen using SEM; (a,b) - untreated; (c,d)-E-mode treatment for $120 \mathrm{~s}$; $(\mathbf{e}, \mathbf{f})-$ H-mode treatment for 5 s. $(\mathbf{a}, \mathbf{c}, \mathbf{e})-5000 \times$ magnification; $(\mathbf{b}, \mathbf{d}, \mathbf{f})-2000 \times$ magnification. 
Likewise, seed surface cracking was also seen in other Fabaceae species. Pea seeds treated with a DBD air plasma exhibited cracks at the surface [12]. Treatment of mung bean seeds in an aqueous solution with an atmospheric pressure microplasma array also eroded and cracked the seed surface [35]. Cracking was also seen in SEM images after plasma treatment of non-legume seed species, such as wheat [45], spinach [46], or cotton [13].

It was previously shown that cracks in the cuticle of soybean facilitate water permeability and thus affect hardness [47]. It, therefore, makes sense that in hard-seeded legumes, seed softening occurs concurrently with the appearance and growth of cracks at the seed surface [40]. Studies of plasma-treated Leucaena leucocephala seeds found that after wetting of the surface, water enters the seed through cracks in the seed coat, which is further increased as plasma enhances the capillary effect in the cracks [9]. A mechanism of improving water absorption due to peeling or cracking of thick seed coat layers was also suggested for plasma-treated spinach seeds, which were normally hard to germinate [46].

Following all of the above findings, we may suggest that the effects of plasma on the outer seed surfaces are such that they contribute to increasing imbibition and loss of hardness.

\subsection{X-ray Photoelectron Spectroscopy}

The alfalfa seed surface composition as determined by XPS is shown in Figure 5 for carbon, oxygen, and nitrogen, as well as in Table 2, for the remaining elements. Figure 5 shows that with increasing plasma treatment time, the carbon concentration decreases, while the oxygen concentration increases up to a plateau. The E-mode treatment results in a final oxygen concentration of about $40 \%$, while the value after the $\mathrm{H}$-mode treatment is about $50 \%$. For the E-mode, the $\mathrm{C}$ decrease and $\mathrm{O}$ increase become statistically significant after treatments of $60 \mathrm{~s}$ and longer. For the H-mode, both differences are significant after treatments of $1 \mathrm{~s}$ and longer. There does not seem to be a trend in the nitrogen concentration fluctuations.

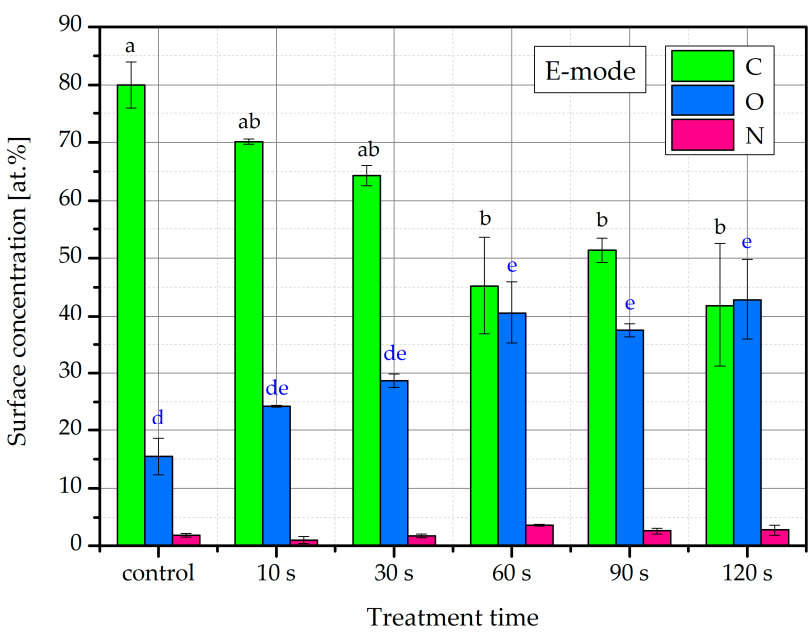

(a)

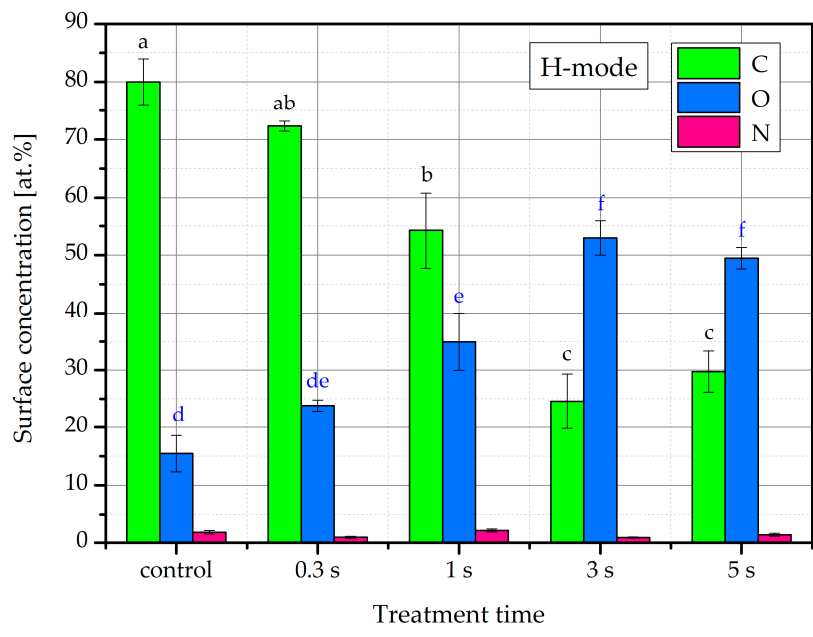

(b)

Figure 5. Alfalfa seed surface concentration of carbon, oxygen, and nitrogen, determined by X-ray photoelectron spectroscopy (XPS), after treatment with (a) - E-mode or (b)-H-mode plasma. The error bars represent standard error. Different lowercase letters above the bars represent statistically significant differences ( $p<0.05$; post hoc Tukey's range tests) between treatments for each individual element ( $\mathrm{C}$ or $\mathrm{O})$. 
Table 2. Alfalfa seed surface concentration of minor elements, determined by X-Ray photoelectron spectroscopy (XPS) after treatment with E-mode or H-mode plasma. Expressed as at.\%; standard error is included.

\begin{tabular}{|c|c|c|c|c|c|c|c|c|}
\hline E-Mode & $\mathbf{F}$ & $\mathrm{Mg}$ & Al & Si & $\mathbf{P}$ & $S$ & $\mathbf{K}$ & $\mathrm{Ca}$ \\
\hline CTRL & & $0.2 \pm 0.2$ & $0.5 \pm 0.2$ & $1.4 \pm 0.4$ & & $0.1 \pm 0.1$ & & $0.6 \pm 0.1$ \\
\hline $10 \mathrm{~s}$ & & $0.1 \pm 0.1$ & & $4.5 \pm 1.0$ & & & & \\
\hline $30 \mathrm{~s}$ & & $0.2 \pm 0.1$ & $0.3 \pm 0.2$ & $3.0 \pm 0.3$ & & $0.1 \pm 0.0$ & $1.2 \pm 0.1$ & $0.4 \pm 0.0$ \\
\hline $60 \mathrm{~s}$ & $0.4 \pm 0.3$ & $0.8 \pm 0.4$ & $1.1 \pm 0.3$ & $3.6 \pm 0.7$ & $0.4 \pm 0.2$ & $0.6 \pm 0.2$ & $1.9 \pm 0.3$ & $1.7 \pm 0.5$ \\
\hline $90 \mathrm{~s}$ & $0.2 \pm 0.1$ & $0.4 \pm 0.1$ & $1.1 \pm 0.2$ & $3.3 \pm 0.9$ & $0.2 \pm 0.1$ & $0.4 \pm 0.2$ & $1.9 \pm 0.2$ & $1.1 \pm 0.2$ \\
\hline $120 \mathrm{~s}$ & & $0.8 \pm 0.4$ & $1.8 \pm 1.1$ & $4.6 \pm 2.1$ & $0.6 \pm 0.3$ & $0.6 \pm 0.2$ & $2.5 \pm 0.4$ & $1.8 \pm 0.9$ \\
\hline H-mode & $\mathrm{F}$ & $\mathrm{Mg}$ & $\mathrm{Al}$ & $\mathrm{Si}$ & $\mathrm{P}$ & S & $\mathrm{K}$ & $\mathrm{Ca}$ \\
\hline CTRL & & $0.2 \pm 0.2$ & $0.5 \pm 0.2$ & $1.4 \pm 0.4$ & & $0.1 \pm 0.1$ & & $0.6 \pm 0.1$ \\
\hline $0.3 \mathrm{~s}$ & & $0.1 \pm 0.0$ & $0.1 \pm 0.0$ & $1.7 \pm 0.2$ & & & $0.7 \pm 0.1$ & $0.3 \pm 0.0$ \\
\hline $1 \mathrm{~s}$ & & $0.9 \pm 0.3$ & $1.1 \pm 0.1$ & $2.9 \pm 0.3$ & $0.2 \pm 0.0$ & $0.6 \pm 0.1$ & $1.1 \pm 0.2$ & $1.9 \pm 0.6$ \\
\hline $3 \mathrm{~s}$ & $1.6 \pm 0.2$ & $2.0 \pm 0.3$ & $1.8 \pm 0.4$ & $5.0 \pm 0.9$ & $0.7 \pm 0.2$ & $1.1 \pm 0.1$ & $4.3 \pm 0.6$ & $5.2 \pm 0.3$ \\
\hline $5 \mathrm{~s}$ & $2.0 \pm 0.3$ & $1.8 \pm 0.1$ & $1.1 \pm 0.3$ & $3.5 \pm 0.6$ & $0.5 \pm 0.2$ & $1.2 \pm 0.0$ & $4.3 \pm 0.8$ & $5.1 \pm 0.4$ \\
\hline
\end{tabular}

To the best of our knowledge, there are no prior published XPS analyses of the alfalfa seed surface, either native or after plasma treatment. However, our observations of decreased surface carbon and increased oxygen are typical for seeds exposed to oxygencontaining plasma. Similar effects have been observed for seeds of several agricultural species, such as wheat [48], quinoa [49], cucumber, and pepper [50]. As for legumes, we have recently demonstrated surface oxidation of bean seeds using the same plasma system as that used here [23]. Comparable effects were also seen on mung bean surfaces after plasma treatment [51].

The mechanism of the increase in oxygen $(\mathrm{O})$ and decrease in carbon $(\mathrm{C})$ surface concentration is the functionalization of the seed surface. The reactive plasma species introduce new, oxygen-containing functional groups to the surface of the seed; the effect was previously confirmed in bean and lentil seeds with the use of time-of-flight secondary ion mass spectrometry (TOF-SIMS) [24]. The reason for the higher final O concentration after $\mathrm{H}$-mode compared to E-mode treatment lies in the considerably higher reactive plasma species density in the H-mode [22].

The only other reported analysis of alfalfa seed surface chemistry after plasma treatment is the Fourier transform infrared spectroscopy (FTIR) by Luan et al. [20]. XPS and FTIR results cannot be directly compared due to different principles and depths of analysis; in addition, the dried seed coat sample in the source paper was ground before FTIR analysis. Nonetheless, the FTIR results suggest increased presence of hydrophilic groups and decrease in hydrophobic ones. e.g., the FTIR analysis showed an increased absorption intensity for peaks belonging to functional groups, such as $\mathrm{O}-\mathrm{H}$ and $\mathrm{N}-\mathrm{H}\left(3284 \mathrm{~cm}^{-1}\right)$, the amide group $\left(1627 \mathrm{~cm}^{-1}\right)$, and $\mathrm{C}-\mathrm{N}\left(1415 \mathrm{~cm}^{-1}\right)$. On the other hand, absorption intensity of peaks belonging to $-\mathrm{CH}_{2}$ (2924 and $2856 \mathrm{~cm}^{-1}$ ) decreased [20]. This indicates that previously hydrophobic molecules of the seed coat were made more hydrophilic by the addition of $\mathrm{O}$ - and N-containing functional groups, and/or removed from the surface to expose the underlying hydrophilic components of the seed cells. Presence of nitrogen-containing groups may originate from these components or from the use of air as process gas.

For the minor elements in Table 2, we mainly see an increase in their surface concentration with increasing treatment time, including some fluctuation of the low concentrations. The most abundant elements reach up to 5 at.\% after the longest treatment times, such as $\mathrm{Si}$ after both treatments or $\mathrm{K}$ and $\mathrm{Ca}$ after $\mathrm{H}$-mode treatment. The origin of the minor elements is expected to be etching of the waxy surface materials, which reveals the cellular structures underneath and thus introduces additional elements into the XPS depth of analysis [52]. Their presence is more abundant after $\mathrm{H}$-mode treatment due to the higher reactive species density and, thus, stronger etching in the H-mode than the E-mode [22]. 


\section{Conclusions}

Using an inductively coupled radio frequency oxygen plasma, we have shown that hydrophilization of alfalfa seeds is possible using both the E-mode and the H-mode. The wettability increase is a consequence of both functionalization and etching of the seed surface. Specific desired effects could be achieved with the fine-tuning of the treatment parameters or combining both plasma modes.

These findings carry a promise that low-temperature plasma could help reduce seed hardness, found not only in alfalfa but in many other legume species. Such a finding would prove beneficial especially if plasma-treated alfalfa seeds would be able to retain the benefits over a prolonged time period, particularly in storage.

As plasma parameters are tunable, it is possible to adjust the intensity of the treatment to achieve the required wettability while at the same time avoid potential seed injury which occurs with mechanical scarification.

The energy consumption per mass of treated seeds is an important parameter for application of plasma systems into agricultural practice. This parameter is rarely tackled in scientific publications. Due to the lack of data on energy consumption, it is difficult to compare the results obtained by the authors listed in Table 1 with those from our own experiment. For a proper assessment, one should compare the energy per volume of treated seeds needed to achieve optimal improvement of the desired seed properties. Indeed, atmospheric pressure plasmas (APPs) are more practical and easier to implement than low-pressure ones, but the ease of implementation is not the only aspect. Lowpressure plasmas have excellent homogeneity and high reactive particle density, are more expensive, and require vacuum conditions, while APPs exhibit extensive gradients and loss of radicals. From an application point of view, plasma-treated water seems promising, but long treatment and seed imbibition times often outweigh its ease of use.

Another advantage of plasma hydrophilization is a reasonably short treatment time, particularly when using H-mode plasma. Combined with the effective hydrophilization at a variety of treatment parameters, as well as the potential for fine-tuning the treatment, plasma modification of alfalfa seed wettability shows promise for introduction into agricultural practices.

Author Contributions: Conceptualization, M.M. and P.G.; methodology, N.R.; investigation, N.R., G.P. and A.V.; writing—original draft preparation, M.H.; writing—review and editing, M.M. and N.R.; supervision, P.G. All authors have read and agreed to the published version of the manuscript.

Funding: This research was funded by the Slovenian Ministry of Economic Development and Technology, grant C2130-19-091009 (Plasma Grain).

Acknowledgments: The authors would like to acknowledge support from the COST action CA19110 (Plasma applications for smart and sustainable agriculture).

Conflicts of Interest: The authors declare no conflict of interest. The funders had no role in the design of the study; in the collection, analyses, or interpretation of data; in the writing of the manuscript, or in the decision to publish the results. Jožef Stefan Institute and Interkorn Ltd. are partners in a research project.

\section{References}

1. Putnam, D.H.; Orloff, S.B. Forage crops. In Encyclopedia of Agriculture and Food Systems; Van Alfen, N.K., Ed.; Academic Press: London, UK, 2014; pp. 381-405. [CrossRef]

2. Wojciechowski, M.F.; Lavin, M.; Sanderson, M.J. A phylogeny of legumes (Leguminosae) based on analysis of the plastid matK gene resolves many well-supported subclades within the family. Am. J. Bot. 2004, 91, 1846-1862. [CrossRef] [PubMed]

3. Acharya, S.N.; Stout, D.G.; Brooke, B.; Thompson, D. Cultivar and storage effects on germination and hard seed content of alfalfa. Can. J. Plant Sci. 1999, 79, 201-208. [CrossRef]

4. Copeland, L.O.; McDonald, M. Principles of Seed Science and Technology, 4th ed.; Springer: New York, NY, USA, 2001.

5. Uradni list Republike Slovenije. Pravilnik o trženju semena krmnih rastlin in pese. 2003. Available online: www.uradni-list.si/ glasilo-uradni-list-rs/vsebina/2003-01-4130 / pravilnik-o-trzenju-semena-krmnih-rastlin-in-pese (accessed on 25 August 2021). 
6. Nelson, S.O.; Stetson, L.E. Long-term effects of radiofrequency, infrared, and gas-plasma treatments on alfalfa seed. Trans. ASAE 1983, 26, 1516-1521. [CrossRef]

7. Ghaleb, W.; Ahmed, L.Q.; Escobar-Gutierrez, A.J.; Julier, B. The history of domestication and selection of lucerne: A new perspective from the genetic diversity for seed germination in response to temperature and scarification. Front. Plant Sci. 2021, 11, 578121. [CrossRef]

8. Hall, J.W.; Stout, D.G.; Brooke, B.M. Alfalfa seed germination tests and stand establishment: The role of hard (water impermeable) seed. Can. J. Plant Sci. 1998, 78, 295-300. [CrossRef]

9. Alves-Junior, C.; da Silva, D.L.S.; Vitoriano, J.O.; Barbalho, A.; de Sousa, R.C. The water path in plasma-treated Leucaena seeds. Seed Sci. Res. 2020, 30, 13-20. [CrossRef]

10. Ambrico, P.F.; Šimek, M.; Morano, M.; De Miccolis Angelini, R.M.; Minafra, A.; Trotti, P.; Ambrico, M.; Prukner, V.; Faretra, F. Reduction of microbial contamination and improvement of germination of sweet basil (Ocimum basilicum L.) seeds via surface dielectric barrier discharge. J. Phys. D: Appl. Phys. 2017, 50, 305401. [CrossRef]

11. da Silva, A.R.M.; Farias, M.L.; da Silva, D.L.S.; Vitoriano, J.O.; de Sousa, R.C.; Alves-Junior, C. Using atmospheric plasma to increase wettability, imbibition and germination of physically dormant seeds of Mimosa caesalpiniafolia. Colloids Surf. B Biointerfaces 2017, 157, 280-285. [CrossRef] [PubMed]

12. Stolárik, T.; Henselová, M.; Martinka, M.; Novák, O.; Zahoranová, A.; Černák, M. Effect of low-temperature plasma on the structure of seeds, growth and metabolism of endogenous phytohormones in pea (Pisum sativum L.). Plasma Chem. Plasma Process. 2015, 35, 659-676. [CrossRef]

13. Wang, X.Q.; Zhou, R.W.; Groot, G.; Bazaka, K.; Murphy, A.B.; Ostrikov, K.K. Spectral characteristics of cotton seeds treated by a dielectric barrier discharge plasma. Sci. Rep. 2017, 7, 5601. [CrossRef] [PubMed]

14. Holc, M.; Mozetič, M.; Recek, N.; Primc, G.; Vesel, A.; Zaplotnik, R.; Gselman, P. Wettability increase in plasma-treated agricultural seeds and its relation to germination improvement. Agronomy 2021, 11, 1467. [CrossRef]

15. Misra, N.N.; Schlüter, O.; Cullen, P.J. Cold Plasma in Food and Agriculture; Academic Press: Cambridge, MA, USA, 2016.

16. Molina, R.; López-Santos, C.; Gómez-Ramírez, A.; Vilchez, A.; Espinós, J.P.; González-Elipe, A.R. Influence of irrigation conditions in the germination of plasma treated Nasturtium seeds. Sci. Rep. 2018, 8, 16442. [CrossRef] [PubMed]

17. Butscher, D.; Van Loon, H.; Waskow, A.; Rudolf von Rohr, P.; Schuppler, M. Plasma inactivation of microorganisms on sprout seeds in a dielectric barrier discharge. Int. J. Food Microbiol. 2016, 238, 222-232. [CrossRef]

18. Tang, X.; Liang, F.C.; Zhao, L.J.; Zhang, L.L.; Shu, J.; Zheng, H.M.; Qin, X.; Shao, C.Y.; Feng, J.K.; Du, K.S. Stimulating effect of low-temperature plasma (LTP) on the germination rate and vigor of alfalfa seed (Medicago sativa L.). In Computer and Computing Technologies in Agriculture IX; Li, D., Li, Z., Eds.; Springer International Publishing: Basel, Switzerland, 2016; pp. 522-529. [CrossRef]

19. Feng, J.; Wang, D.; Shao, C.; Zhang, L.; Tang, X. Effects of cold plasma treatment on alfalfa seed growth under simulated drought stress. Plasma Sci. Technol. 2018, 20, 035505. [CrossRef]

20. Luan, X.Y.; Song, Z.Q.; Xu, W.Q.; Li, Y.B.; Ding, C.J.; Chen, H. Spectral characteristics on increasing hydrophilicity of alfalfa seeds treated with alternating current corona discharge field. Spectrochim. Acta A 2020, 236, 118350. [CrossRef] [PubMed]

21. Machado-Moreira, B.; Tiwari, B.K.; Richards, K.G.; Abram, F.; Burgess, C.M. Application of plasma activated water for decontamination of alfalfa and mung bean seeds. Food Microbiol. 2021, 96, 103708. [CrossRef]

22. Zaplotnik, R.; Vesel, A.; Mozetič, M. Transition from E to H mode in inductively coupled oxygen plasma: Hysteresis and the behaviour of oxygen atom density. Europhys. Lett. 2011, 95, 55001. [CrossRef]

23. Recek, N.; Holc, M.; Vesel, A.; Zaplotnik, R.; Gselman, P.; Mozetič, M.; Primc, G. Germination of Phaseolus vulgaris L. Seeds after a short treatment with a powerful rf plasma. Int. J. Mol. Sci. 2021, 22, 6672. [CrossRef]

24. Bormashenko, E.; Grynyov, R.; Bormashenko, Y.; Drori, E. Cold radiofrequency plasma treatment modifies wettability and germination speed of plant seeds. Sci. Rep. 2012, 2, 741. [CrossRef]

25. Lonlua, R.; Sarapirom, S. The effect of low-pressure plasma treatment on sunflower seed germination and sprouts growth rate. $J$. Phys. Conf. Ser. 2019, 1380, 012157. [CrossRef]

26. Srisonphan, S. Tuning surface wettability through hot carrier initiated impact ionization in cold plasma. ACS Appl. Mater. Interfaces 2018, 10, 11297-11304. [CrossRef]

27. Srisonphan, S.; Ruangwong, K.; Thammaniphit, C. Localized electric field enhanced streamer cold plasma interaction on biological curved surfaces and its shadow effect. Plasma Chem. Plasma Process. 2020, 40, 1253-1265. [CrossRef]

28. Ramkumar, M.C.; Cools, P.; Arunkumar, A.; De Geyter, N.; Morent, R.; Kumar, V.; Udaykumar, S.; Gopinath, P.; Jaganathan, S.K.; Pandiyaraj, K.N. Polymer coatings for biocompatibility and reduced nonspecific adsorption. In Functionalised Cardiovascular Stents; Wall, J.G., Podbielska, H., Wawrzyńska, M., Eds.; Woodhead Publishing: Sawston, UK, 2018; pp. 155-198. [CrossRef]

29. Šerá, B.; Scholtz, V.; Jirešová, J.; Khun, J.; Julák, J.; Šerý, M. Effects of non-thermal plasma treatment on seed germination and early growth of leguminous plants-A review. Plants 2021, 10, 1616. [CrossRef]

30. Pérez-Pizá, M.C.; Cejas, E.; Zilli, C.; Prevosto, L.; Mancinelli, B.; Santa-Cruz, D.; Yannarelli, G.; Balestrasse, K. Enhancement of soybean nodulation by seed treatment with non-thermal plasmas. Sci. Rep. 2020, 10, 4917. [CrossRef] [PubMed]

31. Bormashenko, E.; Shapira, Y.; Grynyov, R.; Whyman, G.; Bormashenko, Y.; Drori, E. Interaction of cold radiofrequency plasma with seeds of beans (Phaseolus vulgaris). J. Exp. Bot. 2015, 66, 4013-4021. [CrossRef] [PubMed] 
32. Solum, D.J.; Lockerman, R.H. Seed coat surface patterns and structures of Oxytropis riparia, Oxytropis campestris, Medicago sativa, and Astragalus cicer. Scanning Microsc. 1991, 5, 779-786.

33. Švubová, R.; Kyzek, S.; Medvecká, V.; Slováková, L.; Gálová, E.; Zahoranová, A. Novel insight at the effect of cold atmospheric pressure plasma on the activity of enzymes essential for the germination of pea (Pisum sativum L. cv. Prophet) seeds. Plasma Chem. Plasma Process. 2020, 40, 1221-1240. [CrossRef]

34. Gao, X.T.; Zhang, A.; Heroux, P.; Sand, W.; Sun, Z.Y.; Zhan, J.X.; Wang, C.H.; Hao, S.Y.; Li, Z.Y.; Li, Z.Y.; et al. Effect of dielectric barrier discharge cold plasma on pea seed growth. J. Agric. Food Chem. 2019, 67, 10813-10822. [CrossRef] [PubMed]

35. Zhou, R.; Zhou, R.; Zhang, X.; Zhuang, J.; Yang, S.; Bazaka, K.; Ken Ostrikov, K. Effects of atmospheric-pressure $\mathrm{N}_{2}$, He, air, and $\mathrm{O}_{2}$ microplasmas on mung bean seed germination and seedling growth. Sci. Rep. 2016, 6, 32603. [CrossRef] [PubMed]

36. De Giorgi, J.; Piskurewicz, U.; Loubery, S.; Utz-Pugin, A.; Bailly, C.; Mène-Saffrané, L.; Lopez-Molina, L. An endosperm-associated cuticle is required for arabidopsis seed viability, dormancy and early control of germination. PLoS Genet. 2015, 11, e1005708. [CrossRef]

37. Grzegorzewski, F.; Rohn, S.; Kroh, L.W.; Geyer, M.; Schlüter, O. Surface morphology and chemical composition of lamb's lettuce (Valerianella locusta) after exposure to a low-pressure oxygen plasma. Food Chem. 2010, 122, 1145-1152. [CrossRef]

38. Billah, M.; Sajib, S.A.; Roy, N.C.; Rashid, M.M.; Reza, M.A.; Hasan, M.M.; Talukder, M.R. Effects of DBD air plasma treatment on the enhancement of black gram (Vigna mungo L.) seed germination and growth. Arch. Biochem. Biophys. 2020, 681, 108253. [CrossRef]

39. Zeng, L.W.; Cocks, P.S.; Kailis, S.G.; Kuo, J. Structure of the seed coat and its relationship to seed softening in mediterranean annual legumes. Seed Sci. Technol. 2005, 33, 351-362. [CrossRef]

40. Zeng, L.W.; Cocks, P.S.; Kailis, S.G.; Kuo, J. The role of fractures and lipids in the seed coat in the loss of hardseededness of six mediterranean legume species. J. Agric. Sci. 2005, 143, 43-55. [CrossRef]

41. Janská, A.; Pecková, E.; Sczepaniak, B.; Smýkal, P.; Soukup, A. The role of the testa during the establishment of physical dormancy in the pea seed. Ann. Bot. 2019, 123, 815-829. [CrossRef] [PubMed]

42. Galussi, A.A.; Arguello, J.A.; Cerana, M.M.; Maximino, M.; Moya, M.E. Anatomical and chemical characteristics of the seed coat of Medicago sativa L. (alfalfa) cv. Baralfa 85 seeds and their association with seed dormancy. Phyton-Int. J. Exp. Bot. 2015, 84, 163-175. [CrossRef]

43. Fadhlalmawla, S.A.; Mohamed, A.A.H.; Almarashi, J.Q.M.; Boutraa, T. The impact of cold atmospheric pressure plasma jet on seed germination and seedlings growth of fenugreek (Trigonella foenum-graecum). Plasma Sci. Technol. 2019, 21, 105503. [CrossRef]

44. Boutraa, T.; Fadhlalmawla, S.A.; M. Almarashi, J.Q.; Mohamed, A.-A.H. Argon cold atmospheric pressure plasma jet enhancing seed germination of fenugreek (Trigonella foenum-graecum). In Proceedings of the IEEE Pulsed Power \& Plasma Science, Orlando, FL, USA, 23-28 June 2019; pp. 1-5.

45. Guo, Q.; Wang, Y.; Zhang, H.; Qu, G.; Wang, T.; Sun, Q.; Liang, D. Alleviation of adverse effects of drought stress on wheat seed germination using atmospheric dielectric barrier discharge plasma treatment. Sci. Rep. 2017, 7, 16680. [CrossRef]

46. Ji, S.H.; Choi, K.H.; Pengkit, A.; Im, J.S.; Kim, J.S.; Kim, Y.H.; Park, Y.; Hong, E.J.; Jung, S.K.; Choi, E.H.; et al. Effects of high voltage nanosecond pulsed plasma and micro dbd plasma on seed germination, growth development and physiological activities in spinach. Arch. Biochem. Biophys. 2016, 605, 117-128. [CrossRef]

47. Ma, F.; Cholewa, E.; Mohamed, T.; Peterson, C.A.; Gijzen, M. Cracks in the palisade cuticle of soybean seed coats correlate with their permeability to water. Ann. Bot. 2004, 94, 213-228. [CrossRef]

48. Molina, R.; Lalueza, A.; López-Santos, C.; Ghobeira, R.; Cools, P.; Morent, R.; de Geyter, N.; González-Elipe, A.R. Physicochemical surface analysis and germination at different irrigation conditions of DBD plasma-treated wheat seeds. Plasma Process. Polym. 2020, 18, e2000086. [CrossRef]

49. Gómez-Ramírez, A.; López-Santos, C.; Cantos, M.; García, J.L.; Molina, R.; Cotrino, J.; Espinós, J.P.; González-Elipe, A.R. Surface chemistry and germination improvement of quinoa seeds subjected to plasma activation. Sci. Rep. 2017, 7, 5924. [CrossRef]

50. Štěpánová, V.; Slavíček, P.; Kelar, J.; Prášil, J.; Smékal, M.; Stupavská, M.; Jurmanová, J.; Černák, M. Atmospheric pressure plasma treatment of agricultural seeds of cucumber (Cucumis sativus L.) and pepper (Capsicum annuum L.) with effect on reduction of diseases and germination improvement. Plasma Process. Polym. 2018, 15, 1700076. [CrossRef]

51. Varnagiris, S.; Vilimaite, S.; Mikelionyte, I.; Urbonavicius, M.; Tuckute, S.; Milcius, D. The combination of simultaneous plasma treatment with $\mathrm{Mg}$ nanoparticles deposition technique for better mung bean seeds germination. Processes 2020, 8, 1575. [CrossRef]

52. Holc, M.; Junkar, I.; Mozetič, M. Plasma Agriculture: Oxygen Plasma Effects on Garlic; Cambridge Scholars Publishing: Newcastle upon Tyne, UK, 2020. 